\title{
EL ZOO DE CRISTAL. UN TRANVÍA LLAMADO DESEO \\ Tennessee WILLIAMS / Ramón ESPEJO (ed. y trad.)
}

(Madrid: Cátedra, 2019, 382 págs.)

Hoy, por fin, los lectores disponen de dos de las grandes obras de Tennessee Williams en una versión española fidedigna, rigurosa y con las garantías de haber sido preparada por un gran especialista en teatro norteamericano, a quien se deben las más importantes aportaciones dentro del mundo hispánico y, particularmente, de los montajes realizados en España.

Frente a la ingente bibliografía existente en inglés sobre este dramaturgo desde los años cuarenta del siglo XX, en nuestra lengua los trabajos resultan muy limitados y el lector culto apenas podía recurrir hasta este momento a más que a un puñado de publicaciones de relevancia relativa, pues incluso los estudiosos de lengua materna española en general han escrito sus análisis en el idioma de Williams: por ejemplo, del mismo profesor de la Universidad de Sevilla Espejo Romero podía leerse desde 2014 una aproximación al teatro de este autor en España, en la que recorría la sucesión de puestas en escena por los grupos de teatro universitario, de cámara y de ensayo durante la posguerra, hasta el primer montaje realizado por una compañía profesional en 1957, publicada en Tennessee Williams and Europe. Intercultural Encounters, Transatlantic Exchanges (edición de John S. Back, en Amsterdam, Rodopi). Igualmente, se contaba con sus análisis del sentido que adquirían los montajes de este autor y sus coetáneos norteamericanos en el contexto político español del franquismo, amén de en otras contribuciones, en el magnífico y definitivo trazado histórico en tres tomos The History of the Performance of American Plays in Spain, 1912-1977: Theatre As a Weapon Against Political Authoritarianism (Lewiston, Edwin Mellen, 2017).

Las versiones españolas de El zoo de cristal y de Un tranvía llamado deseo existentes hasta 2019 no podían por sí mismas garantizar al 
comprador potencial su fidelidad al texto inglés de Williams, pues casi en ningún caso contaban con indicaciones sobre la versión tomada como base para su traslado al español: la que de Un tranvía llamado deseo imprimió la editorial Escelicer de 1962, efectuada por el conocido traductor de Dickens José Méndez Herrera y hoy descatalogada, suscitaba al lector común la sospecha de haber sufrido las incursiones de la censura; la de León Mirlas, que desde 1949 ha publicado repetidamente la editorial Losada, presentaba elecciones de traducción que desorientaban sobre el auténtico sentido ideado por el autor, incluso en algunas de las intervenciones más importantes de los personajes. La del gran experto en guiones literarios Enrique Llovet se acomodaba bien a las exigencias escénicas, como se demostró en el montaje del Teatro Bellas Artes, en la temporada 19931994, pero a partir de ahora el lector preferirá la de Espejo, que ofrece mejores avales científicos.

En cuanto a El zoo de cristal, la edición de 1964, realizada por los críticos y colaboradores de La Estafeta Literaria José Gordon y José María de Quinto e impresa por Alfil, se había empleado ya en las representaciones de teatro de cámara de los años cincuenta y suponía una adaptación conforme con la época que se vivía en España y sus consabidas restricciones. Las posteriores, muchas de ellas preparadas para los distintos montajes habidos en España en los últimos sesenta años, cuentan, por lo general, con las mismas limitaciones que las habidas respecto a Un tranvía llamado deseo.

Gracias al profesor Espejo, el interesado por estas obras dispone no solo de traducciones fiables, sino de una guía sintética y precisa, sencilla, práctica y manejable para su comprensión general, en el estudio introductorio; unas explicaciones pertinentes, en las notas, sobre las connotaciones y los sentidos más ligados al contexto de las intervenciones de los personajes; comentadas sucinta y certeramente, las investigaciones más notables de cada obra en torno a los aspectos sustanciales y, además, datos exactos sobre las diferentes versiones y ediciones en inglés.

Por otra parte, en esta edición quedan explicitadas las razones y los criterios por los que el profesor de la universidad sevillana ha elegido, entre los posibles, los textos a partir de los cuales traducir: de El zoo de cristal, la edición para ser leída, preferida por el propio Williams y recogida en las obras completas de 1971; de Un tranvía llamado deseo, la que también allí aparece, que a su vez seguía la primera edición, de 1947. 
Espejo también expone el modo de resolver, en sus personales traducciones, las peculiaridades del lenguaje de Williams y las distintas hablas impresas a los personajes según la condición de cada uno, hablas llenas de modismos y referencias locales sin equivalencias castellanas; hablas de los años cuarenta del siglo XX cuyo traslado a la lengua española corría el riesgo de perder el sabor de época. Las decisiones adoptadas demuestran la importancia de que sea un auténtico experto en el autor y su época, en la obra y en los personajes, quien vierta en su propia lengua este tipo de piezas.

Además de todos estos aspectos, Espejo repasa en su introducción los principales datos sobre la trayectoria del dramaturgo, los estrenos, la recepción de estas dos obras y su sentido en el conjunto de la producción de Williams, como también concreta los montajes y versiones cinematográficas más conocidos, incluidos los verificados en España.

En su revisión de los personajes y de las técnicas empleadas, proporciona un resumen y a veces confrontación de las opiniones mejor argumentadas por los críticos desde las primeras representaciones, en una selección sumamente iluminadora y con frecuencia relegada a las notas para satisfacer a los lectores más apasionados sin abrumar a los bisoños. Con ella, invita a ampliar la información unas veces, otras avisa sobre la obsolescencia de determinados planteamientos pero, sobre todo, aporta perspectivas personales que denotan una sensibilidad literaria y social independiente de esquemas en ocasiones, si bien calibrando siempre las divergencias de costumbres de la época respecto a las de hoy: su reivindicación de la complejidad de los personajes, el señalamiento de las contradicciones que los convierten en únicos y les confiere carácter humano incluso en su modo de oponerse a los demás, revoca la cierta univocidad hacia la que se orientaban las tendencias tradicionales de interpretación, y las enriquece sin desecharlas. Si bien en la misma línea de algunas investigaciones novedosas, Espejo revela el alcance universal de cada uno de los personajes creados por Williams en estas obras, al tiempo que los relaciona, según determinadas facetas de cada uno de ellos, con los creados por otros autores o con diferentes grupos sociales del siglo XX.

En lo concerniente a los recursos escenográficos, la revisión de Espejo proporciona al lector las claves para atender adecuadamente a la plasticidad y los símbolos en las dos piezas editadas (la luz y la iluminación, la distribución y segmentación del espacio escénico, los 
espacios representados, la música, los ruidos y sonidos, el vestuario, la utilería...), de modo que no pase inadvertida al lector despistado o centrado en los diálogos. Así mismo, el valor de las proyecciones en El zoo de cristal con las que Williams seguía las propuestas de Piscator, queda relativizado, pero también explanado en sus justos términos, tanto por el hecho de que se estrenara sin ellas en Chicago y Nueva York como porque habitualmente se hayan criticado o se prescinda de ellas en los montajes.

A todo esto se añade una interesante atención hacia las posibilidades de nuevos los acercamientos que se vienen anunciando y efectuando en los últimos años. Con ellos se demuestra la universalidad latente en estas obras, aparentemente vinculadas con una situación histórica y unas coyunturas circunscritas a los personajes.

Sin duda, el trabajo de este gran estudioso no solo contará con el beneplácito de lectores comunes y estudiantes, con mayor o menor grado de cultura y especialización, sino que podrá facilitar las tareas a los encargados de los nuevos montajes escénicos en España, para que resplandezcan los elementos que puedan conectar con los espectadores, hacerles reflexionar, cuestionar y replantearse cuanto vean en el escenario.

Ana Isabel Ballesteros Dorado Universidad CEU-San Pablo 